\title{
Renovation as a core of conceptual models of relationship for innovative types of reorganization of digitalized cyber-physical systems of construction objects throughout their life cycle
}

\author{
Vitaliy Chulkov, and Muhammet Fakhratov* \\ Moscow State University of Civil Engineering, 129377, Moscow, Russia
}

\begin{abstract}
The problem of reorganization, as many types of rearrangement in the dyad 'man-equipment' ('operator-equipment' in transport; 'workerequipment' in mechanical engineering; 'tenant-building' in construction and in housing and communal services), is constantly relevant in a developing society. Modeling of ways and forms of solving this problem, the study of different types of reorganization in the dyad 'man-equipment', rationing their characteristics and identifying rational areas of their application in the construction industry of our country has been going on since the first half of the 20th century. Scientific studies of the reorganization problem, the proposed functioning models of each of the types of construction reorganization, formation and improvement of regulatory documents of construction production provide effective activities of construction organizations and a necessary level of quality of processes and results of construction production. At the beginning of the 20th century, the main type of construction reorganization was 'repair', which by the middle of the century was divided into three distinguishable categories: repair as such, reconstruction and restoration. Each of these categories has individual properties, characteristics and a range of functioning. The basis for this division was social need. At the end of the 20th century, social phenomena of Russian reality again required a revision of the categories of construction reorganization, therefore, construction science proposed innovative types of construction reorganization (renovation, reversal, recomposition, retreatment, etc.). Each type was a response to a new manifestation of social requirements, all types were equally relevant. Only in the second decade of the 21 st century, the urban planning and building production reacted to these achievements of the national building science and chose renovation as a basic type of innovative building. The article discusses a renovation model (П-graph of innovative types of construction reorganization), which allows analysis (downscaling, disintegration) and synthesis (enlargement, integration) of concepts, levels and results of construction reorganization processes.
\end{abstract}

\footnotetext{
* Corresponding author: eng.civil2004@gmail.com
} 


\section{Introduction}

From the twenties of the past century to the present, three traditional types of object reorganization have been regularized in the directive and regulatory documentation of the construction industry of our country: repair (planned, current, capital, etc.), reconstruction and restoration [1, 2, etc.].

During major repairs, an object is returned to a condition suitable for operation and corresponding either to the project of its initial construction or to one of the implemented subsequent modifications of this project.

During reconstruction, an architectural and construction appearance or the purpose of an object is changed, using its preserved fragments or their descriptions, using traditional and new materials, products, processes and systems (completion, superstructure, expansion, movement, etc.). This is a complex of construction and installation works and organizational and technical measures that change the operating conditions of the building, make up for losses from physical and moral wear and tear, bring the object to compliance with current norms and rules [3, 4, etc.].

During restoration, the objects are monuments of history, culture and art, they are restored in the form corresponding to a certain historical period of the functioning of these objects, they eliminate the effects of time, climatic conditions and human activities.

The creative time of 'perestroika' of the 90 s of the 20th century objectively brought to life a group of new (innovative) types of reconstruction: recomposition, technical rehabilitation, renovation, reversal, and retrieval.

Recomposition (recombination) is an arrangement of the components of something in a new order with elements of innovation, improving living comfort on a new technical basis. The term was proposed by K.A. Schreiber and applied to the rebuilding by S.V. Kuznetsov (2004 [5]).

Technical rehabilitation is a comprehensive restoration of functional systems of a building object using energy-saving technologies, materials and systems according to standard projects without evacuation of residents. Rehabilitation is comparable in investment costs to overhaul or reconstruction. After reunification in 1990, Germany has thirty years of experience in the comprehensive rehabilitation of socially oriented (mainly panel) housing [6], where rehabilitation measures are divided into • energetically compulsory (insulation of roofs, attics, facades, basement ceilings; replacement of windows and balcony doors; updating heating systems, hot water supply and ventilation); - energetically optional (waterproofing roofs and foundations; replacing plumbing equipment; tiling kitchens and bathrooms; updating power supply systems; adding new or updating existing balconies and loggias; repair of stairwells; updating the entrance doors of apartments; creating an architecturally expressive image of the building).

The name of another type of innovative building remodeling (renovation) is compliant with the Latin term renovatio (renovation, renewal, reconstruction), however, different users put across different meanings. Referring to the practice of foreign building reconstruction, Vedeneev N.S. and Maklakova T.G. in the 1990s proposed to use the term 'renovation' in the educational and methodical literature of construction universities $[7,8,9$, etc.]. In support of the need for infill construction, the Deputy of Moscow Mayor for Urban Development Resin V.I. introduced the term 'renovation' in the policy documents of the Government of Moscow. At the beginning of 2017, a law was passed on the demolition of five-story buildings in Moscow [10], which confirmed the idea of renovation in the Moscow Government: forced release of the territory (demolition of buildings and structures, removal of utilities, networks, etc. from the underground space) to ensure a possibility of new construction, regardless of the degree of preservation of the buildings located on it. There are alternative opinions on the meaning of the term 'renovation' [11]. 
Renovation is divided into:

- forced (urban areas demolished according to officially adopted decisions);

- evolutionary - naturally occurring and resulting from accumulated errors or unaccounted consequences, or not fully controlled and uncontrolled cyclic recompositions and / or reversals.

- Evolutionary renovation is the result of a lack of: $\bullet$ possibility to diagnose and monitor the current state of an object according to its safety criteria; - methods and models of accounting and analysis of a combination of results officially registered (accounted for) or performed bypassing the official order of local building redevelopment. The ultimate form of evolutionary renovation is an accident, destruction of an object, or a more serious emergency.

Reversal - a change in the purpose, legal status and ownership of the property being redeveloped. The term was proposed by Chulkov V.O. and applied to construction redevelopment by Golubeva N.N. (2004 [12]).

Retrieval (from the English retrieve - restore, find) - bringing the reconstructed object into good condition by attaching an old functional system of the building to a new system, providing the possibility of replacing elements of the new system locally or as a whole (using the principle of assembly-disassembly) and ensuring elimination of obsolescence of the building and a normal operation of the facility. The main functional structure of a building is an old functional system, and mounted systems for finishing buildings, structures and their interior are a new functional system. The term was proposed by Chulkov V.O. and applied to building redevelopment by Kuzina O.N. (2010 [13, 14, etc.]).

\section{Research methodology}

Systemic, comparative and qualitative analysis, infographic modeling and anthropotechnical management have been selected as the basis of the study.

\section{Research results}

The types of building reconstruction included in the second group can hardly be called 'completely new' or 'completely innovative'. An attentive and impartial researcher will discover their manifestation, with more or less activity, at any of the historical stages of domestic and foreign construction practice in different types of building reconstruction included in the first group. Until a certain time, they were not displayed in a concentrated form as independent varieties of building reconstruction.

In our country, the types of building reconstruction of the first group (repair, reconstruction, restoration) are products of the previous social formation, they are focused on maintaining stability (repair of a room or an apartment, reconstruction of a building complex or an architectural ensemble, restoration of a cultural monument, etc.). The second group of varieties of building reconstruction in modern conditions of managing and social structure of our country is aimed at reconstruction (destruction of the existing and creation of the new) in line with the business approach.

The objectification and positioning of renovation, recomposition, reversal, and retrieval in modern conditions of management and social structure can be explained by elimination of a tough command-administrative approach, under which such varieties of construction restructuring were 'invisible' (according to the principle: 'there is no such thing in the standards, so there is no such thing in rea life!').

A complete list, structure, and relationships of all potentially possible characteristics of a building reconstruction are never realized simultaneously. Such a multitude has rational 
redundancy, which ensures a complete mutual compatibility of varieties of the building reconstruction. It is necessary to distinguish and systematize these varieties (Fig. 1).

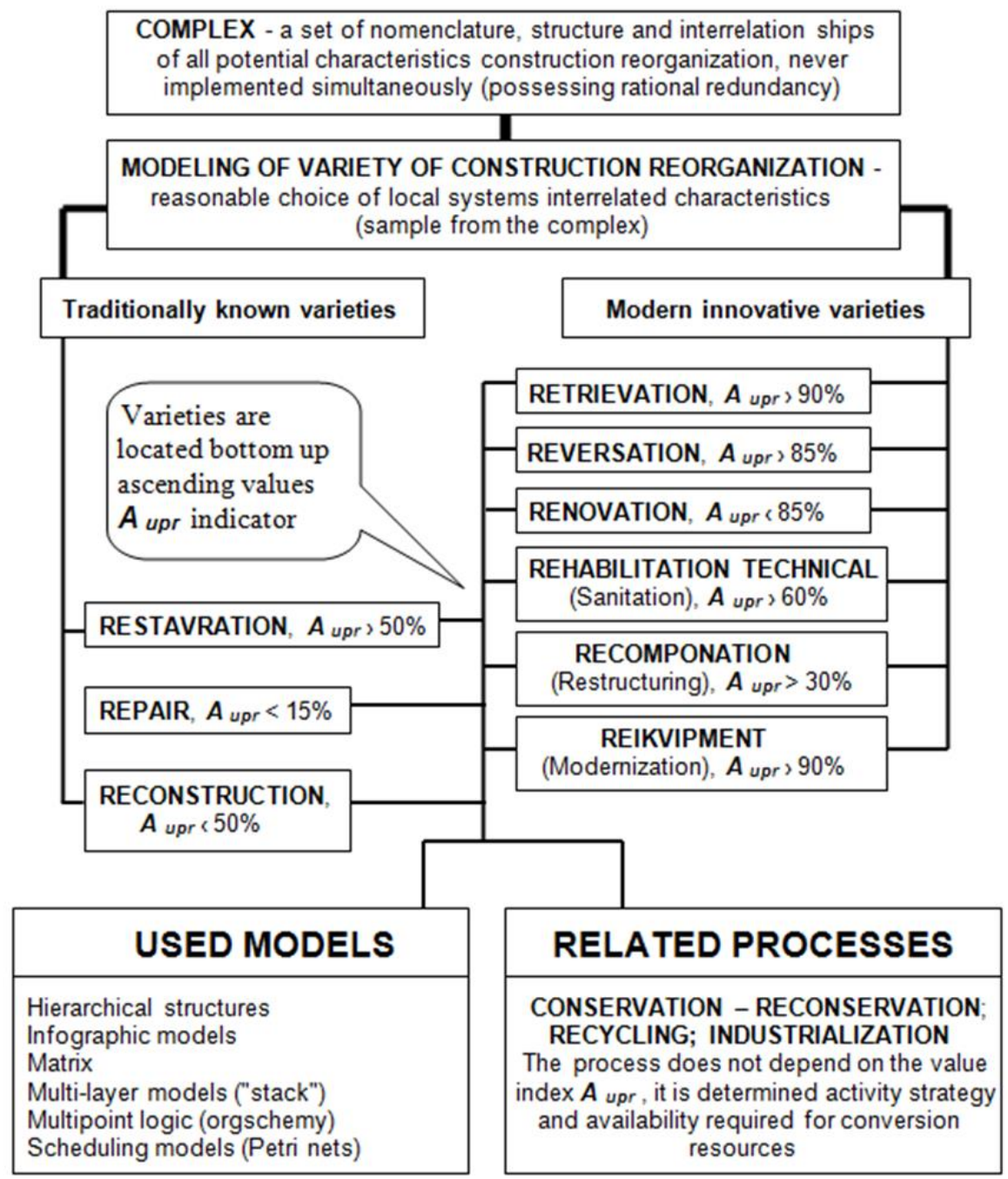

Fig.1. Distinguishing and systematizing the types of building reconstruction (Chulkov V.O., 2010).

The criterion for distinguishing and systematizing the building reconstruction types is the volume of the used part of the original $\varphi$ resource (as a percentage) originally included in the project of the building reconstruction object.

The meaning of this functional resource for each kind of building reconstruction is different. For example, during retrieval, such a resource is the area of the surface to be finished inside the premises or the outer surface of a building or a structure being rebuilt.

Since during retrieval the surface requiring finishing, in most cases, ranges from $90 \%$ to $100 \%$ of the entire surface of the room (or the outer surfaces of external walls of a building or a structure), for this type of building reconstruction $\varphi>90 \%$ [13].

The results of statistical studies of modern Russian construction enterprises and organizations $[13,14$, etc.] allow us to determine approximate values of $\boldsymbol{\varphi}$ for each of the types of building reconstruction mentioned above (Table 1). 
Table 1.

\begin{tabular}{|c|c|}
\hline Name of the building reconstruction type & $\begin{array}{c}\text { Value of } \\
\varphi\end{array}$ \\
\hline \multicolumn{2}{|c|}{ Group of well-known varieties of building reconstruction } \\
\hline Repair & $<15[\%]$ \\
\hline Reconstruction & $<50[\%]$ \\
\hline Restoration & > 50[\%] \\
\hline \multicolumn{2}{|c|}{ Group of innovative varieties of building reconstruction } \\
\hline Recomposition (restructuring) & > $30[\%]$ \\
\hline Technical rehabilitation & $>60[\%]$ \\
\hline Renovation & $<85[\%]$ \\
\hline Reversal & $>85[\%]$ \\
\hline Retrieval & $90[\%]$ \\
\hline
\end{tabular}

The given values of $\varphi$ are not normative, but they allow to specify the area of arising new innovative varieties of building reconstruction to meet various needs. Such needs are produced by: - representatives of public and private ownership businesses, joint ventures, holdings and holding companies, associations; - market conditions for construction products; - innovative technologies of building production; • numerous construction participants (investors; developers; customers; designers; managers; contractors; suppliers; transport, operating and research organizations); - owners and users-operators of construction objects (buildings and structures).

\section{Discussion of the results}

In the period of 2015-2020, the urban planning and construction operation responded to the achievements of domestic construction science and decided to choose renovation as the basic type of innovative building reconstruction [10]. Previously equivalent innovative types of building reconstruction are now forced to conceptually determine the relationship with renovation. Let us consider two possible conceptual models (Fig. 2 and 3).

The first conceptual model (П-graph by S.M. Efimova [15, 16, etc.], Fig. 2) interprets renovation as the core of innovative building reconstruction. This defining type of reorganization in building reconstruction has its own goals and objectives but turns to other traditional and innovative types of reconstruction as necessary.

The formal algebraic model of a $\Pi$-graph, as shown in $[15,16$, etc.], differs from the previously known algebra by Codd E.F. (Codd E.F., 1971 [17]) and allows a comparative analysis of network and relational models for studying the types of building reconstruction.

Manipulating informal relations between construction and installation operations in the process of reconstruction of objects allows us to formally set the sequence of work with data based on multi-sorted calculus of first-order predicates with tuple terms.

The body of $\Pi$-graph (the core of innovative building reconstruction) corresponds to the name of an elementary information unit (type of reorganization 'renovation'). Each leg [15] of a П-graph is associated with a natural number (the number of the leg or its 'label'), a specific attribute value or a whole tuple of some relation. A П-graph is assigned to a domain, and a network of $\Pi$-graphs is assigned to a tuple and a relation. 


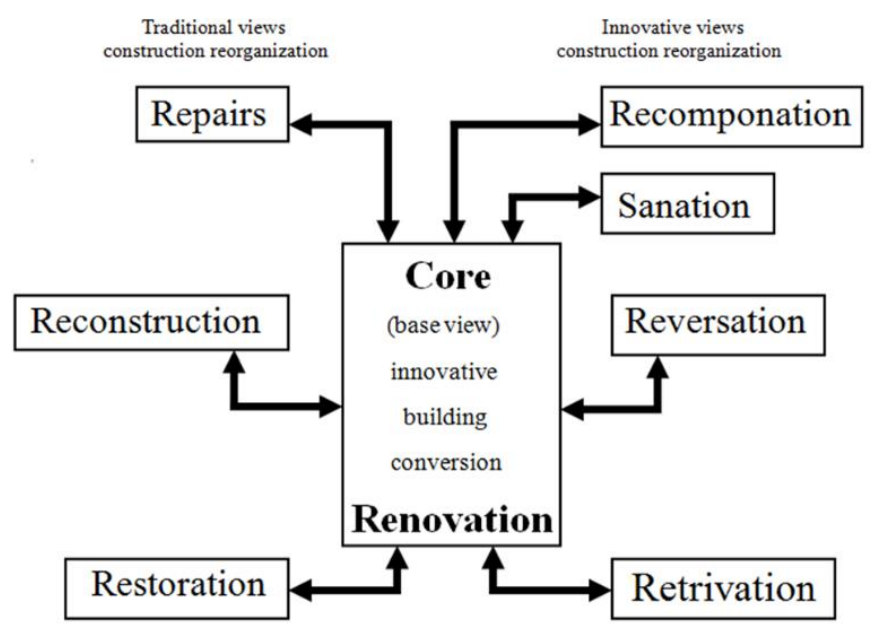

Fig. 2. Renovation as the core of a 'spider-graph' model of interconnection of innovative types of construction reorganization (Chulkov V.O., 2017)

When the core of a $\Pi$-graph changes, the same nomenclature of innovative types of building reconstruction can form new variants of this conceptual model.

$\Pi$-graphs can be 'linked' to each other by legs having at least one identical label in the sets marking them. Such a linkage (both in single-layer and in multi-layer infographic models [18]) allows to enter the relationship between specific values of different elementary information units.

The second conceptual model ('spinner' according to Kievskiy I.L. [19], Fig. 3) interprets renovation as the center of the orbit of interconnected 'spinners'.

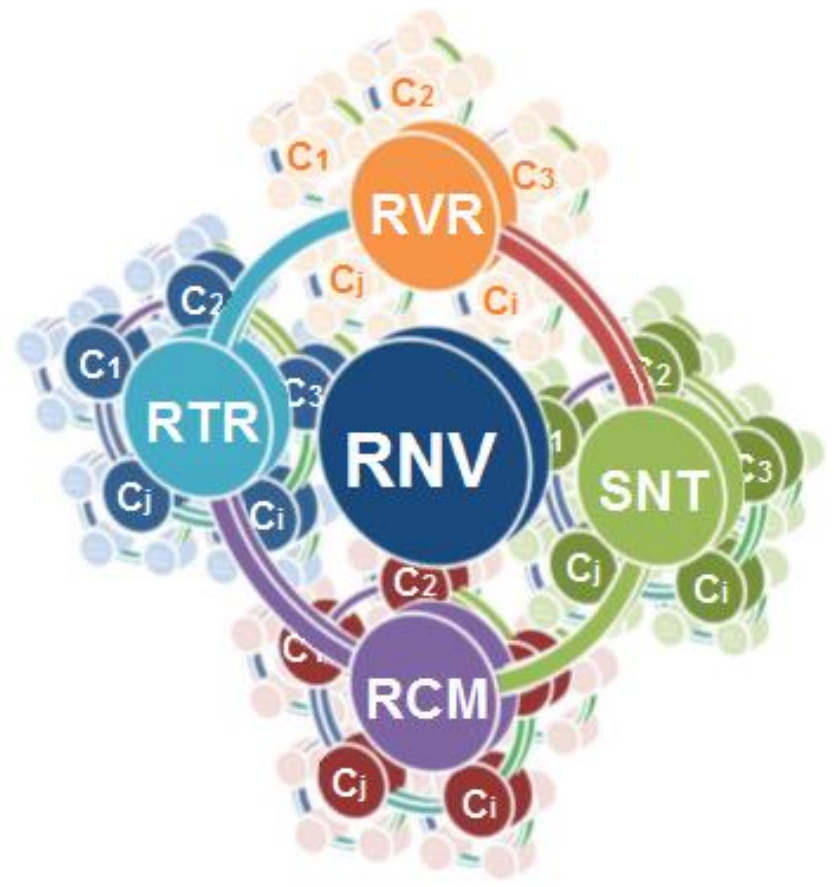


Symbols of innovative types of reorganization: RNV - renovation; RTR - retrevation; RVR reversation; SNT - sanitation; RCM - recombination; $\mathbf{C 1}, \mathbf{C 2}, \mathbf{C 3}, \ldots, \mathbf{C i}, \ldots \mathbf{C j}$ - properties or components of a specific innovative type of reorganization.

Fig. 3. An infographic model of the structure of innovative types of reconstruction using the principle of interconnected 'spinners' according to I.L. Kievskiy [19] (Chulkov V.O., 2019).

This is the managing center for the use of various innovative types of reorganization in building reconstruction, setting goals and defining the tasks of the remaining innovative types of reconstruction within the framework of the applied construction organization [20].

The totality of the considered models of innovative types of structural reconstruction and their relationship is still 'open'. It can be supplemented with the development of society, the widespread introduction of 'informatics' into a person's life (a narrow area of cybernetics [21]), and into his home and production activities - digitalized [22, 23 etc.] cyber-physical engineering service systems [ 24-29 etc.] and digital economy systems [3034 etc.].

\section{Conclusion}

1. The innovative types of building reconstruction have a similar algorithm of their emergence and formation: - arguing the need, they identify the local component of the known variety of building reconstruction (Table 1); $\bullet$ give this component the status of a new separate type of building reconstruction; - form directive and administrative documentary support of a new kind of building reconstruction; $\bullet$ make a new separate type of building reconstruction a multivariate object of business activity; $\bullet$ form the variety of its organizational and technological varieties; - normalize the processes of activity, indicators and quality levels of the results of a new kind of building reconstruction.

2. Here are some examples of implementation of such an algorithm: $\bullet$ a well-known local component of reconstruction - 'redevelopment', if necessary, can be transformed into an independent version of the reconstruction - 'recomposition'; $\bullet$ a local component of the repair, 'restoration of the initial state', if necessary, can be transformed into an independent variety of reconstruction - 'reversal', etc.

\section{References}

1. L.G. Dickman, Organization of Construction Production, Textbook for construction universities (Publishing House ASV, M., 2002)

2. V.O. Chulkov, R.R. Kazaryan, B.A. Levin, Infographic Models of Anthropotechnics of Management: A modular course of lectures. (Educational edition in 3 v., Ed. by V.O. Chulkov. - 1200 p., Ill)

3. Overhaul and Reconstruction https://dmstr.ru/articles/chem-kapitalnyy-remontotlichaetsya-ot-rekonstrukcii/ Access date 15.2.2020

4. The Tax Code of the Russian Federation dated 05.08.2000 N 117-FL (as amended on 21/06/2011). Part Two. Article 257.

5. S.V. Kuznetsov, Computer-Aided Design of Recombination of Conditionally Autonomous Housing Projects (Abstract. of diss. of cand. tech. sciences. - 05.13.12.Defended on 16.01.2004.- TSNIIOMTP, 2004)

6. What Is Done with Five-Story Buildings in Europe: Reconstruction Instead of Renovation, https://varlamov.ru/2359727.html Access date 15.2.2020 
7. T.G. Maklakova, Renovation of Urban Development, Residential Buildings and Complexes. Study guide (MISI, M., 1993)

8. T.G. Maklakova, I.V. Aksenova, Reconstruction of Civil Buildings (Operations manual for term papers on reconstruction of civil buildings for students of specialties 'Industrial and Civil Engineering' and 'Building Design', MGSU, 2002)

9. V.O. Chulkov, E.N. Shilina, Design of Housing in the Context of Housing Renovation Considering Organizational and Technological Criteria, Bulletin of Eurasian Science 2, (2019) https://asj.today/PDF/104SAVN219.pdf (free access)

10. The Law of the Russian Federation 'On the Status of the Capital of the Russian Federation' and certain legislative acts of the Russian Federation regarding the establishment of the regulation specifics of certain legal relations for the renovation of housing stock in the subject of the Russian Federation - the city of federal status Moscow (as amended on June 14, 2017)

11. I. Petrov, Interview: 'Architect Yuri Ekhin: how Moscow renovators deceive citizens' on April 29, 2017. https://newizv.ru/interview/29-04-2017/arhitektor-yuriy-ehinrenovatory-moskvy-obmanyvayut-grazhdan -i-prezidenta-76f3e1a5-97ed-4cac-860509b673591481 Date of access 10.2.2020

12. N.N. Golubeva, Computer-Aided Design of Urban Territories Reorganization with a Change of their Intended Purpose (Abstract. diss. cand. tech. sciences. - 05.13.12.Defended on 18.03.2004.- TSNIIOMTP, 2004)

13. V.O. Chulkov, O.N. Kuzina, Organizational and Technological Criteria for Systematization of Varieties of Construction Restructuring, Management of investment-construction and housing and communal complexes, International collection of scientific papers, Ed. by V.O. Chulkov, MGAKHiS, M., 410-426 (2010)

14. A. Volkov, L. Kievskiy, O. Kyzina, The Development of Moscow Office Real Estate Market and Key Features for System Approach Application, Advanced Materials Research, 1065-1069, 2534-2537 (2014)

15. S.M. Efimova, On Algebraic Approach to the Problem of Knowledge Representation, Situational Control and Semiotic Modeling (Collection of inform. materials about complex. prob. 'Cybernetics'. - VK-100.- M.: NS complex. prob. 'Cybernetics' of the Academy of Sciences of the USSR, 1983) pp. 54-73

16. S.M. Efimova, ח-graphs for Representation of Knowledge, Messages on Applied Mathematics of the Computing Center of the Academy of Sciences of the USSR (Editorin-Chief D.A. Pospelov, VTs AS USSR, M., 1985)

17. E.F. Codd, Relational Completeness of Data Base Sublanguages (Courant Computer Science Symposia 6, Data Base Systems, New York City, May 24-25, Printece-Yall, 1971)

18. V.O. Chulkov, Modeling of Digitalization of Management in Cyber-Physical Systems of Reorganization of Residential Territories, Advances in Economics, Business and Management Researchol 105, 640-644 (2019) doi.org/10.2991/iscde-19.2019.124

19. I.L. Kievskiy, Management and Coordination of Large-Scale Urban Projects of Dispersed Construction in the City of Moscow through the Example of Renovation, In Collection: Renovation. Large-scale urban project of distribution-building construction, M., Russian School, 11-33 (2018).

20. L.V. Kievskiy, Applied Organization of Construction, Vestnik MGSU 12(3)(102), 253259 (2017) doi: 10.22227 / 1997-093535.2017. 3.253-259.

21. K. Steinbuch, Informatik: Automatische Informationsverarbeitung, SEG-Nachrichten (Technische Mitteilungen der Standard Elektrik Gruppe), Firmenzeitschrift, (1957). 
22. National Digitalization [Electronic resource] https: // rostec.ru/analytics/natsionalnayatsifrovizatsiya / (Date of access: 08/10/2019).

23. V.G. Khalin, G.V. Chernova, Digitalization and its Impact on the Russian Economy and Society: Advantages, Challenges, Threats and Risks, Management Consulting 10, 46-63 (2018).

24. Cyber-Physical System https://en.wikipedia.org/wiki/ Cyber-physical system (Date of access: 05/06/2019)

25. R.G. Sanfelice, Analysis and Design of Cyber-Physical Systems. A Hybrid Control Systems Approach, Cyber-Physical Systems: From Theory to Practice (D. Rawat, J. Rodrigues, I. Stojmenovic, CRC Press, 2016) ISBN 978-1-4822-6333-6.

26. E.A. Lee, The Past, Present and Future of Cyber-Physical Systems: A Focus on Model Cheng AMK, ed., Sensors (Basel) 15(3), 4837-4869 (2015)

27. L. Chernyak, Cyber-Physical Systems at the Start, Open Systems, DBMS 2, 10-15. (2014) https://www.osp.ru/os/2014/02/ 13040038 (Date of access: 05/06/2019).

28. V.Ya. Tsvetkov, Cyber-Physical Systems, International Journal of Applied and Fundamental Research 6-1, 64-65 (2017) https://appliedresearch.ru/ru/article/view?id=11623 (Date of access: 29.09.2019).

29. N.A. Yastreb, Industry 4.0: Cyber-Physical systems, Reasonable Environment, Internet of Things. https://techno.vogu35.ru/docs/2015/Industria_4_0_Yastreb.pdf (Date of access: 29.09.2019).

30. A.V. Keshelava, V.G. Budanov, V.Yu. Rumyantsev and others; under the general. ed. of A.V. Keshelava, Introduction to Digital Economy (VNIIGeosystem, 2017). (On the threshold of the 'digital future.' Book One)

31. V.D. Markova, Digital Economy (INFRA-M, M., 2020). www.dx.doi.org/10.12737/textbook_5a97ed07408159. 98683294.- Text: electronic. http://znanium.com/catalog/product/ 1043213

32. https://creativeconomy.ru/lib/39059 On Formation of 'Homo Digital' Model and Competition of Social Groups under Technological Transformation of Everyday Reality: View of Economic Theory / I.N. Makarov [et al.]//Russian Entrepreneurship. 2018. - Volume 19, No. 4. - pp. 855-866. https://creativeconomy.ru/lib/39059

33. Development of Digital Economy in Russia. The program until 2035. [Electronic resource] http://innclub.info/wpcontent/uploads/2017/05 / strategy. pdf 